\title{
Choroidal Metastasis as the Initial Presentation of Rectal Adenocarcinoma
}

\author{
FNU Amisha ${ }^{1}$, Tanvi Harishbhai Patel ${ }^{2}$, Shubham Biyani ${ }^{3}$, Prachi Saluja ${ }^{1}$, Nitesh Gautam ${ }^{1}$, Sunilkumar Kakadia ${ }^{4}$ \\ 1.Department of Internal Medicine, University of Arkansas for Medical Sciences, Little Rock, Arkansas, USA \\ ${ }^{2}$ Department of Internal Medicine, Baptist Health - University of Arkansas for Medical Sciences, North Little Rock, Arkansas, USA \\ ${ }^{3}$ Department of Neurology, University of Arkansas for Medical Sciences, Little Rock, Arkansas, USA \\ ${ }^{4}$ Haematology/Oncology Division, Department of Internal Medicine, University of Arkansas for Medical Sciences, Little Rock, Arkansas, USA
}

Received: $12 / 11 / 2021$

Accepted: $16 / 11 / 2021$

Published: $15 / 12 / 2021$

How to cite this article: Amisha FNU, Patel TH, Biyan S, Saluja P, Gautam N, Kakadia S. Choroidal metastasis as the initial presentation of rectal adenocarcinoma. EJCRIM 2021;8: doi:10.12890/2021_003059.

Conflicts of Interests: The authors declare there are no competing interests.

This article is licensed under a Commons Attribution Non-Commercial 4.0 License

\section{ABSTRACT}

Choroidal metastasis from rectal cancer is a rare occurrence with limited literature on appropriate evidence-based treatment options. We describe the case of 44-year-old man who presented with left-sided painful vision loss who was found to have left choroidal and multiple lung metastasis from an unknown primary which was later found to be rectal adenocarcinoma.

\section{LEARNING POINTS}

- Ocular metastasis from colorectal cancer is rare with choroid being the most common site of involvement if it occurs.

- Ocular metastasis usually occurs as a part of generalized metastasis to multiple organ systems.

- Treatment options include systemic chemotherapy, radiation, bevacizumab and enucleation.

\section{KEYWORDS}

Rectal adenocarcinoma, colorectal cancer, choroidal metastasis, ocular metastasis, case report

\section{INTRODUCTION}

The choroid is the most common (54\%) ocular site for metastatic disease because of the abundant vascular supply from the posterior ciliary artery ${ }^{[1]}$. Other common sites for ocular metastasis are the orbit (26\%), the ciliary body (14\%), the iris (10\%) and the eyelid (10\%). If choroid metastasis is found, $47 \%$ of the primary cancers are breast cancer, $21 \%$ lung cancer, $4 \%$ gastrointestinal tract cancer, $2 \%$ skin melanoma, $2 \%$ renal cell carcinoma and $2 \%$ prostate cancer. Choroid metastasis from colorectal cancer is rare worldwide, possibly because of the long course through multiple vascular beds from the colorectal site to the eyeball with many anatomical barriers ${ }^{[2]}$. Due to the rarity of the condition, there is a paucity of succinct evidence-based data on demographic characteristics, treatment, duration of treatment and outcomes, with data limited to case reports. We carried out an extensive electronic search of Google Scholar, Medline (PubMed) and Embase for other similar published cases in the English language, which are summarized in Table 1.

\section{CASE DESCRIPTION}

A 44-year-old Caucasian man presented to our facility with left eye pain and partial vision loss for 8 days. In addition, he also reported left-sided pleuritic chest pain, subjective fevers, unintentional weight loss of approximately 10 pounds, and alternating diarrhoea with constipation with intermittent bloody bowel movements for the last 2 months. His medical history included essential hypertension, intravenous drug use 3 years previously, current heavy smoking ( 11 packs per day for 25 years) and alcohol use ( 2 standard drinks/day). He denied pain, floaters or vision changes in the right eye. 


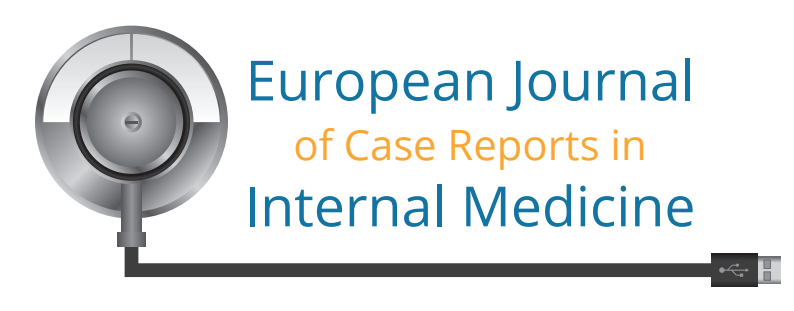

\begin{tabular}{|c|c|c|c|c|c|c|c|c|c|c|c|}
\hline 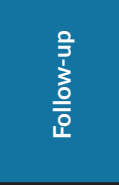 & 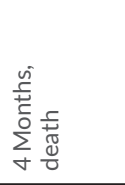 & 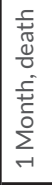 & 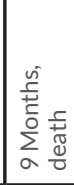 & 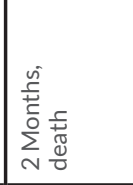 & 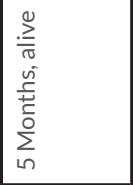 & 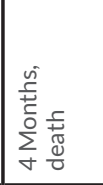 & 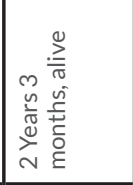 & 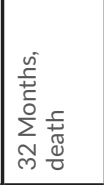 & 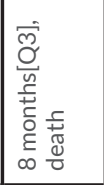 & 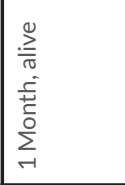 & 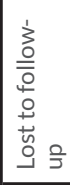 \\
\hline 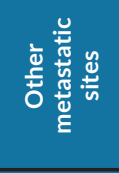 & $\stackrel{\text { 号 }}{3}$ & \begin{tabular}{|l}
\multicolumn{5}{c}{} \\
$\overline{\tilde{v}}$ \\
$\frac{0}{0}$ \\
$\frac{0}{<}$ \\
\end{tabular} & 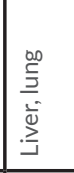 & 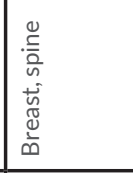 & 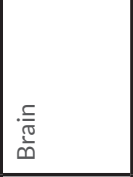 & 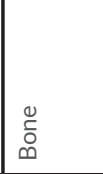 & 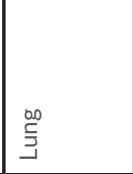 & 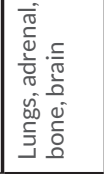 & 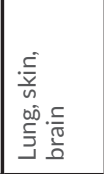 & 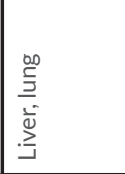 & 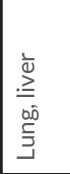 \\
\hline 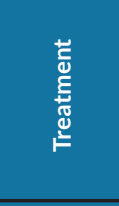 & 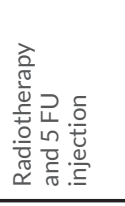 & 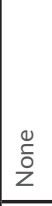 & 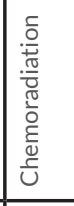 & 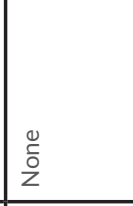 & 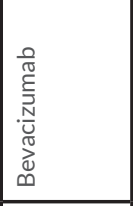 & 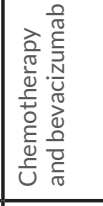 & 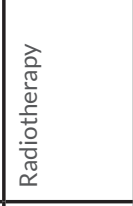 & 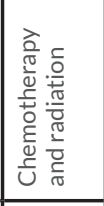 & 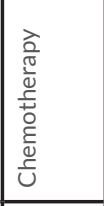 & 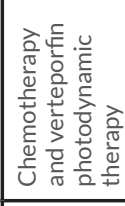 & 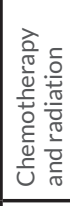 \\
\hline 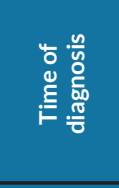 & 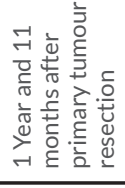 & 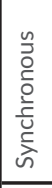 & 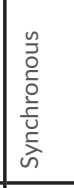 & 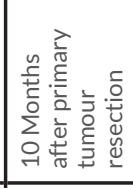 & 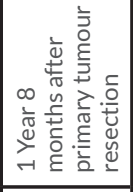 & 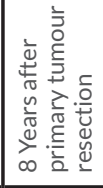 & 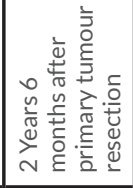 & 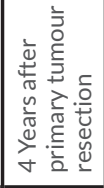 & 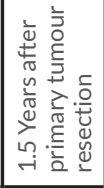 & $\begin{array}{l}n \\
\sum^{n} \\
\sum_{0}^{0} \\
\sum_{\infty} \\
\infty\end{array}$ & 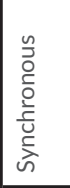 \\
\hline 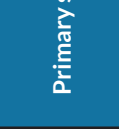 & 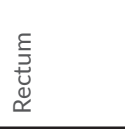 & $\frac{\text { 흥 }}{\text { o }}$ & 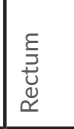 & 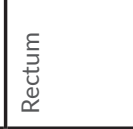 & 흥 & 흥 & 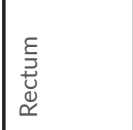 & 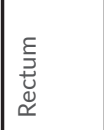 & 흥 & $\frac{\sigma}{0}$ & 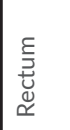 \\
\hline 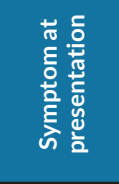 & 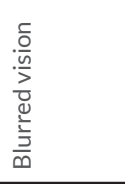 & 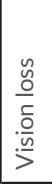 & 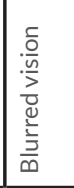 & 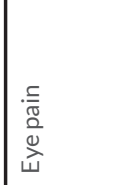 & 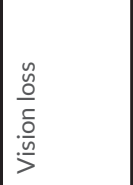 & 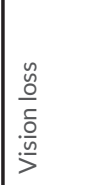 & $\begin{array}{l}\frac{\pi}{0} \\
\frac{0}{0} \\
0 \\
\frac{d}{\pi} \\
0 \\
\frac{\partial}{\Sigma} \\
\Sigma\end{array}$ & 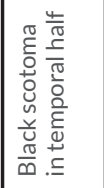 & 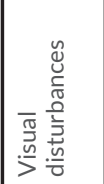 & 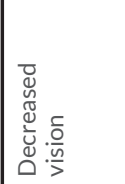 & 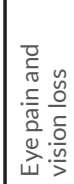 \\
\hline 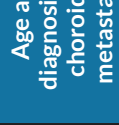 & 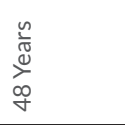 & 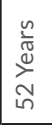 & 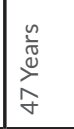 & 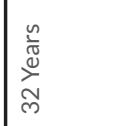 & 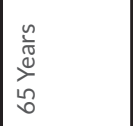 & 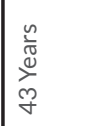 & 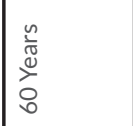 & 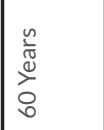 & 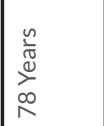 & 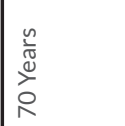 & 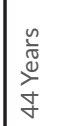 \\
\hline 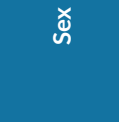 & $\begin{array}{l}\frac{0}{\tilde{\Phi}} \\
\frac{\tilde{W}}{\omega}\end{array}$ & 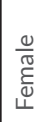 & $\frac{\frac{0}{\sigma}}{\Sigma}$ & 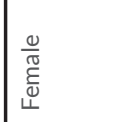 & 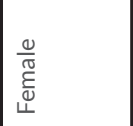 & $\frac{\frac{0}{\sigma \pi}}{\Sigma}$ & $\frac{\frac{0}{\pi}}{2}$ & 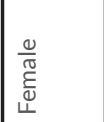 & 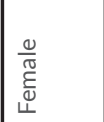 & $\frac{\frac{0}{\sigma \pi}}{\sum}$ & $\frac{\frac{0}{\sigma}}{\frac{\pi}{2}}$ \\
\hline 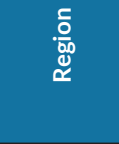 & 兰 & 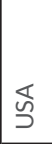 & 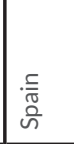 & \begin{tabular}{|l}
$\frac{\pi}{0}$ \\
$\frac{\pi}{\pi}$ \\
$\frac{\pi}{2 \pi}$ \\
$\frac{\pi}{2}$
\end{tabular} & 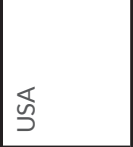 & 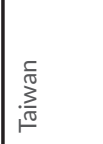 & 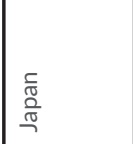 & 芯 & 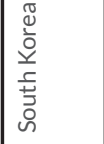 & \begin{tabular}{|l}
$\overline{\bar{N}}$ \\
$\bar{N}$ \\
$\overline{0}$
\end{tabular} & 壱 \\
\hline ֻ & 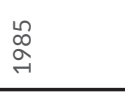 & ¿্ণ & $\begin{array}{l}\text { Oे } \\
\text { Oे }\end{array}$ & ¿̊ & $\begin{array}{l}\infty \\
\text { ò } \\
\end{array}$ & 㝏 & 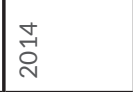 & 吕 & 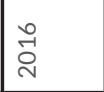 & ते & స్. \\
\hline 总 & 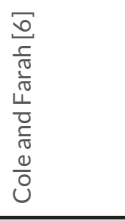 & 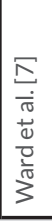 & 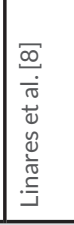 & 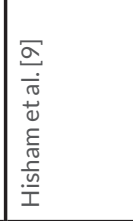 & 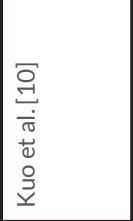 & 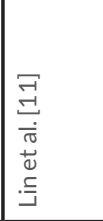 & 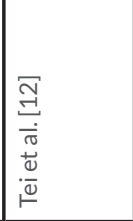 & 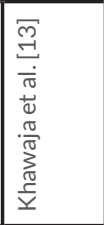 & 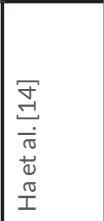 & 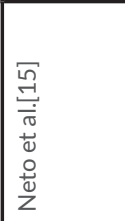 & 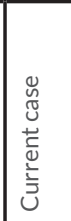 \\
\hline
\end{tabular}


On examination, visual acuity on Snellen's chart was: right (R) eye 20/30 and left 20/20 (L) eye, and intraocular pressure (IOP) was R eye 15 and L eye 42. On visual field examination, the left eye had total superior temporal, inferior temporal, superior nasal and inferior nasal visual field deficiencies, light reflex was present and there was no afferent pupillary defect. On slit lamp examination, the left eye had upper eye lid oedema, chemosis, early cystic oedema, a shallow anterior chamber and a forward bowed iris; the vitreous was not visualized. On fundoscopy B scan, a temporal mass occupying $40-50 \%$ of the globe was seen in the left eye and lattice degeneration with atrophic changes/ holes with pigmentation in the right eye.

Initial laboratory investigations including complete blood counts, chemistry and liver function tests were within normal limits. Infectious work-up for hepatitis, human immunodeficiency virus and Treponema pallidum was negative. Transthoracic echocardiography revealed no evidence of vegetations. Computed tomographic (CT) imaging of the maxillofacial region showed a left globe posterior chamber mass measuring $1.4 \times 2.1 \mathrm{~cm}$ arising from the lateral wall without extension into surrounding tissue. To further evaluate the systemic symptoms, $\mathrm{CT}$ of the chest/abdomen and pelvis was obtained, which revealed bilateral lung and hilar masses, multiple hypodense hepatic lesions in the right and left lobe up to $4.2 \mathrm{~cm}$ in size, splenomegaly, and a $2.5 \mathrm{~cm}$ rectal mass with perirectal lymphadenopathy. Interventional radiology-guided biopsy of the liver mass was suggestive of rectal adenocarcinoma; investigations showed epithelial neoplasm with foci of gland formation, positive CDX-2 and pan cytokeratin, negative CK20, CK7, synaptophysin, chromogranin, mucicarmine, trichrome and iron. There was loss of MLH1 and PMS2 nuclear expression and intact nuclear expression for MSH2 and MSH6. The patient was started on acetazolamide 500 mg twice daily, dorzolamide-timolol, latanoprost, prednisolone acetate and brimonidine eye drops for acute angle closure glaucoma. He was started on concurrent chemoradiation with FOLFOX (folinic acid, 5-flurouracil and oxaliplatin). He was lost to follow up after three cycles of radiation.

\section{DISCUSSION}

The ocular symptoms in cases of choroidal metastasis include, but are not limited to, blurred vision, decreased visual acuity, visual field disturbance, double vision, eye pain, hyperaemia, glare and eye movement disorder, flashes and floaters. However, 9-11\% of patients are asymptomatic, and lesions can be seen on routine ocular examination ${ }^{[1,2]}$. Choroidal metastases generally appear as a yellow subretinal mass associated with subretinal fluid but can also appear as an orange, brown-grey mass. Sites of the metastases include superior (22\%), inferior (17\%), lateral (35\%), nasal (14\%) and macular (12\%) locations. The differential diagnosis includes choroidal melanoma, haemangioma, granuloma, osteoma and sclerochoroidal calcification ${ }^{[1]}$.

Magnetic resonance imaging is the most common method used for diagnosis. Biopsy is needed for confirmation but should be performed with consideration for the patient's life expectancy due to the high risk of bleeding and blindness ${ }^{[2]}$. The current literature contains few recommendations regarding the appropriate treatment of choroidal metastasis from colorectal cancer, but an aggressive multidisciplinary approach is recommended. Treatment options for symptomatic choroidal metastases depend on systemic status and staging of the metastatic disease, and options include observation, systemic chemotherapy, radiotherapy, intravitreal bevacizumab therapy or even enucleation for blind and painful eyes harbouring metastatic tumours ${ }^{[3,4]}$. Our patient was started on concurrent chemoradiation with FOLFOX but was lost to follow-up after three cycles of radiation and hence his ultimate ou tcome is unknown. Photodynamic therapy is a non-thermal laser modality that can be used. It works through induction of necrosis and apoptosis, damage to intratumoral vasculature and a local inflammatory reaction ${ }^{[4]}$. Bevacizumab is a recombinant humanized antibody against all isoforms of VEGF-1. It has antiangiogenic and antipermeability effects on new tumour vessels and smaller lesions ${ }^{[5]}$. The prognosis for choroidal metastasis from colorectal cancer is poor. It is recommended that all treatment options, side effects and prognosis are discussed with the patient before any treatment is started. 


\section{REFERENCES}

1. Arepalli S, Kaliki S, Shields CL. Choroidal metastases: origin, features, and therapy. Indian J Ophthalmol 2015;63(2):122.

2. Huo SM, An HJ, Lee JE, Eum SH, Kim MY, Jang YN, et al. Choroidal metastasis from colon cancer treated with palliative radiotherapy. Korean J Med 2015;89(6):723-727.

3. Tei M, Wakasugi M, Akamatsu H. Choroidal metastasis from early rectal cancer: case report and literature review. Int J Surg Case Rep 2014;5(12):1278-1281. https://doi. org/10.1016/j.ijscr.2014.10.059

4. Neto LB, Pulido JZ, Melo GB, Lima LH, Rodrigues EB. Photodynamic therapy of presumed choroidal metastasis secondary to colorectal carcinoma: literature review. Case Rep Ophthalmol Med 2020;2020:6490535. https://doi.org/10.1155/2020/6490535

5. Lin CJ, Li KH, Hwang JF, Chen SN. The effect of intravitreal bevacizumab treatment on choroidal metastasis of colon adenocarcinoma--case report. Eye (London) 2010;24(6):1102-1103. https://doi.org/10.1038/eye.2009.257

6. Cole MD, Farah NB. The choroid - an unusual site for metastasis in patients with adenocarcinoma of the rectum - a case report. Eur J Surg Oncol 1985;11:275-278.

7. Ward SD, Byrne BJ, Kincaid MC, Mann ES. Ultrasonographic evidence of a mushroom-shaped choroidal metastasis. Am J Ophthalmol $2000 ; 130: 681-682$.

8. Linares P, Castanon C, Vivas S, Diz P, Garcia-Palomo A, Llano C. Bilateral choroidal metastasis as the initial manifestation of a rectal cancer. J Gastroenterol Hepatol 2004;19:726727.

9. Hisham RB, Thuaibah H, Gul YA. Mucinous adenocarcinoma of the rectum with breast and ocular metastases. Asian J Surg 2006:29:95-97.

10. Kuo IC, Haller JA, Maffrand R, Sambuelli RH, Reviglio VE. Regression of a subfoveal choroidal metastasis of colorectal carcinoma after intravitreous bevacizumab treatment. Arch Ophthalmol 2008;126:1311-1313.

11. Lin CJ, Li KH, Hwang JF, Chen SN. The effect of intravitreal bevacizumab treatment on choroidal metastasis of colon adenocarcinoma - case report. Eye (Lond) 2010;24:11021103.

12. Tei M, Wakasugi M, Akamatsu H. Choroidal metastasis from early rectal cancer: case report and literature review. Int J Surg Case Rep 2014;5(12):1278-1281. doi:10.1016/j. ijscr.2014.10.059

13. Khawaja MR, Minturn JT, Spittler AJ, Chiorean EG. Ocular metastasis of colorectal cancer: an uncommon presentation of a common malignancy. Hematol Oncol Stem Cell Ther 2015;8(4):176-180. https://doi.org/10.1016/j.hemonc.2015.02.002

14. Ha JY, Oh EH, Jung MK, Park SE, Kim JT, Hwang IG. Choroidal and skin metastases from colorectal cancer. World J Gastroenterol 2016;22(43):9650-9653. doi:10.3748/wjg. v22.i43.9650

15. Neto LB, Pulido JZ, Melo GB, Lima LH, Rodrigues EB. Photodynamic therapy of presumed choroidal metastasis secondary to colorectal carcinoma: literature review. Case Rep Ophthalmol Med 2020;2020:6490535. https://doi.org/10.1155/2020/649053 